\title{
Gender-Informed Mentoring Strategies for Women Engineering Scholars: On Establishing a Caring Community
}

\author{
NAOMi C. CHesler \\ University of Vermont \\ MARK A. Chesler \\ Department of Sociology \\ University of Michigan
}

Department of Mechanical Engineering

\section{ABSTRACT}

Improved mentoring of women graduate students and young faculty is one strategy for increasing the presence, retention and advancement of women scholars in engineering. We explore the sociological literature on interpersonally- and institutionallygenerated gender roles and dynamics that make the construction and maintenance of mentoring relationships especially difficult for women in male-dominated fields. In addition, we review nontraditional strategies including peer-, multiple- and collective mentorships that are likely to be more successful for most women (and many men). Finally, organizational change strategies designed to provide a more egalitarian and cooperative atmosphere in engineering programs and departments are presented. These ideas represent a social contract for a caring community more supportive of all members' personal and professional growth and success.

\section{INTRODUCTION}

Our primary concern in this paper is with strategies for improving the presence, retention, and advancement of women graduate students and faculty in engineering. We focus on mentoring as a key element in such strategies. Progress on the broader agenda, of which mentoring is one important aspect, is significant for several reasons. First, it should lead to improved interest by and retention of women in engineering at all educational levels. Success in this area would significantly increase the talent pool in engineering programs, create a more diverse community in institutions of higher education and in the engineering workplace more generally. Second, it will likely lead to greater equality and equity in the academy - that is, more equal access to resources and rewards, and freedom from either bias or favoritism. Third, it is likely to improve the quality and climate of our profession, leading to greater achievements for all members of the engineering community.

\section{WOMEN SCHOLARS IN SCIENCE, MaTHEMATICS, AND ENGINEERING: THE PROBLEMS}

Of engineers with doctorate degrees employed at four-year colleges and universities in 1997, less than $7 \%$ were women [1]. Of the engineering faculty nationwide in 1991, 7\% of Assistant Professors were women, 3\% of Associate Professors were women, and only $1 \%$ of Full Professors were women [2]. The science, mathematics, and engineering (SME) gender gap at the faculty level is mirrored in academic medicine and the higher ranks of the industrial sector. While the proportion of women attending medical school has increased steadily over the last decade [3], a significantly smaller proportion of women than men advanced from Assistant to Associate Professor, and from Associate to Full Professor in the medical academy [4]. Female leadership in the upper echelon of the business community is also rare: women comprise only $10 \%$ of senior managers and less than $4 \%$ of the uppermost ranks (CEO, president, executive vice president and $\mathrm{COO}$ ) in Fortune $500 \mathrm{com}-$ panies; and are less than 3\% of top corporate earners [5].

How do we account for the disproportionate absence of women in the higher technical and managerial ranks of our society and in SME disciplines and professions in particular? Although there are important differences across racial and class groupings, the effects of early schooling experiences and family socialization cannot be ignored. For example, young women typically place a greater priority on interpersonal satisfaction and integration than do men, potentially resulting in different career (and life) priorities [6]. Moreover, women more often prioritize concerns for group affiliation over individual achievement and value egalitarianism, community, collaboration and diversity more than their male counterparts [7, 8]. An encapsulation of socialized gender differences between women and men in our culture is given in Table 1 . We readily acknowledge that this rubric does not apply to everyone; a bell-curve distribution likely exists allowing significant individual variation and crossover between socialization patterns.

The socialization of women as compared to men is particularly relevant to their success in the sciences and engineering, because women are often less confident in and more alienated by the culture of fields that do not fit with their own learned styles. That traditional SME education has emphasized individual competition and offered few opportunities for cooperative and interactive learning may have contributed to the loss of women in the recent past $[9,10]$. In a 1995 report, the National Research Council Board on Engineering Education emphasized the importance of creating a positive, supportive climate for undergraduate engineers as an alternative to the "boot camp" or "weed out" nature of some engineering 


\begin{tabular}{|l|c|c|}
\hline & Female & Male \\
\hline Motivation & Encouragement & Challenge \\
\hline Group Interaction & Integrated & Separated \\
\hline Task Engagement & Collaborative & Competitive \\
\hline Vision of Success & Group Affiliation & $\begin{array}{c}\text { Individual } \\
\text { Achievement }\end{array}$ \\
\hline
\end{tabular}

Table 1. Outcomes of female and male socialization on characteristics and goals (adapted from reference [6]).

programs [11]. Indeed, adverse reactions to negative pedagogical and peer group experiences leads to higher "switch rates" (rates at which people leave SME for other fields) among women undergraduates as compared to men with similar grades $[12,13]$. While many undergraduate curricula are being revised to encourage collaboration and integration, reform of graduate programs lags far behind. Furthermore, the strategies being explored for retaining and promoting women undergraduate students provide only a starting place for what is needed at the graduate and post-graduate or faculty levels. At these academic later stages, women are a small minority and the culture is predominantly male-oriented; the engineering academy may, thereby, be considered "gendered."*

Women who successfully pursue careers in science and engineering despite these challenges often face additional difficulties in their interpersonal relationships and self-esteem. Anecdotal evidence suggests many men find women in engineering either "unnatural" or unfeminine, marginalizing them through the use of pejoratives such as ugly, sexually deviant, or suggesting they are too smart or "too busy to be attractive" $[11,14]$. When these perceptions, and related behaviors, are acted out in the classroom, hallways and faculty meetings, observed by students, and tolerated by colleagues, they are reinforced in the lives of both men and women. These barriers prevent many women from succeeding in SME fields and contribute to the "leaky pipeline" of women in engineering at both the masters and doctoral levels [10]. Since these discriminatory patterns continue in the lives of women faculty, women must enter and find their way in a "chilly climate" [15]. Once in these environments, the familial and care-taking roles expected of women as wives and mothers compete with academic demands. Cole [16] refers to the combination of these patterns as the "accumulating disadvantages" or barriers to the success of women in science. While these disadvantages and barriers are slowly lessening, and more women are present and becoming successful in SME, much more progress needs to be made. The hope is to increase the number of women scholars who enter, stay, and advance in engineering by creating a supportive research, teaching, and service environment with approachable, accessible senior faculty of either gender.

\section{MENTORING AS A SOLUTION}

We hold no illusion that these issues will be eliminated simply by improved mentoring of women graduate students and faculty in

*It is worth noting that the gendered nature of any organization may be invisible to both men and women. Indeed "gender may be deeply hidden in organizational processes and decisions that appear to have nothing to do with gender" but are "embedded and recreated daily in organizational activities, most of which do not appear to be gendered" [8]. science and engineering. However, improved mentoring of women can have significant impact on their careers and lives, and on the academic climate and structure more generally. Indeed, quantitative studies on mentor functions and outcomes in organizations have shown that both formal and informal mentoring are effective in promoting protégé advancement and compensation [17]. Moreover, Ambrose et al. provide biographical summaries of successful women in these fields who consistently report the personal importance of effective and caring mentors [18]. In addition, "women faculty members who have thrived appear to have in common two significant characteristics: ... they all identify sufficiently positive relationships with their own graduate school advisors as crucial... (and)... all of these dedicated women labor to interpret an appropriate role as advisor to their female students" [14]. We are particularly concerned with formulating mentoring strategies informed by the gender socialization of women and the current operation of a male milieu in the engineering academy; strategies which are designed to meet the needs of both women and men.

\section{A. Traditional Mentoring Models}

Mentoring is traditionally a developmental relationship in which an experienced person provides both technical and psychosocial support to a less experienced person. In return, the mentor gains personal satisfaction, respect from colleagues for successfully developing younger talent, and in the best case grows intellectually as well. One of the earliest discussions of mentoring is found in Greek mythology, wherein Athena, the Goddess of wisdom and the civilized life, protects and guides Odysseus on his journeys and prompts him to find the courage to act in the face of many dangers. She also appears in the form of a man-Mentor- to guide his son Telemachus, and to urge him to search for news of his father.

Mentoring has multiple aspects and functions, and has variously been described as fulfilling either or both the technical and psychosocial needs of the less experienced person. Examples of the technical knowledge-based or career development issues include how to solve a particular technical problem, continue intellectual growth, approach a new internship, job or course, develop a syllabus or field project, prepare a research proposal, balance work overloads, present an appeal to a faculty member or department chair, ask for an assignment change, and learn the "unwritten rules" of the organization (e.g., dress codes, address titles, social styles and norms). Mentors and protégés also may address psychosocial issues such as how to deal with difficult peer or faculty relationships or personality conflicts, balance school, work and family pressures, respond to sexism and discrimination, establish a sense of competence, cope with disappointment, find courage, and grow as a person. The traditional conception of mentoring poses accomplishing such objectives within a two-person, mentor-protégé relationship [19].

1) The Heroic Journey: In the context of the male-dominated academy, especially in the sciences and engineering, the mentoring of both younger men and women generally has proceeded on the basis of a cultural style more suited to men. Two major components typify this approach to mentoring: (1) the priority of informational and technical conversation, relationships, and guidance over psychosocial issues; and (2) the commitment to "the heroic journey." Research with young men and women in science and engineering suggests that men have "a predominantly instrumental approach to education...contrasted with an affective orientation among many young women" [10]. Thus, the mentoring model that emphasizes technical 
and instrumental issues is well suited to the preponderance of traditionally-socialized men in these fields; at the same time, it does not fit well with the ways in which most women were socialized.

Seymour further describes the male socialization metaphor underpinning most traditional mentoring relationships as focusing on challenging the protégé, posing tasks in order to increase the young person's tolerance to stress (and, potentially, to weed out those who cannot rise to the challenge), and stressing independence [10]. Broome $[20,21]$ applies the works of Robert Bly and Joseph Campbell in discussing "the heroic engineer" and "the heroic mentorship." The hero's journey, in this interpretation, requires separation from dependency -including abandonment by former helpers, sole engagement in perilous adventure, and triumphant return. As Broome indicates, on this journey "the helper abandons the hero, leaving him or her eventually to slay the dragon" [20]. The denial of nurturing in the midst of stressful situations is presumed to lead to healthy independence and stems from traditional "tests of manhood" present in military and sport arenas. It also often leads to the highly competitive situation that Baum has called "the boot camp environment where one's success comes only at the failure of others" [22]. Reconsidering the gender patterns outlined in Table 1, this style clearly does not fit the socialization and styles of most women and their orientations to integration rather than separation, interdependence rather than either dependence or independence, and collaborative rather than competitive task engagement. Perhaps not as obviously, it also does not fit well for many men socialized in less gender-constricted ways.

2) Cross-Gender (and Cross-Race) Mentoring: That dominant mentoring style in science and engineering is based on a traditional model of male socialization is not the only impediment to successful mentoring of women scholars. It is also true that in these maledominated fields there are few senior female faculty available to act as mentors and models. Indeed, young people generally prefer to work with mentors and role models who are like themselves (probably because they perceive that these models will have experienced difficulties and challenges similar to their own [23]), and this is especially difficult for women in science and engineering fields. Seymour and Hewitt report that "women in departments with no female faculty at all experienced more difficulty than other women in believing that their own presence in the major was normal" [24]. The presence of a single token woman is not much better, since multiple female role models are important to send the message that there are alternative ways to be a woman in science. The result is, as Wankat and Oreovicz note, "Women faculty get less faculty support than men but need more" [25].

Even when senior women are present and available, junior women may not develop mentoring relationships with them for several reasons. First, when senior women are perceived as being outside the departmental norm, they will be less appealing mentors to young women attempting to construct their own personal and professional personae. A recent University of Michigan guide for graduate students notes, "faculty of color, female faculty, and [Lesbian, Gay, Bisexual and Transgender] faculty are aware that some graduate students do not select them as mentors because of their marginalized positions in the academy. Graduate students perceive that these faculty wield less power and influence inside and outside their department... and are therefore seen as being less effective on providing the types of instrumental assistance graduate students need" [26].

Second, a real lack of power and influence in their department may make senior women less effective mentors for their protégés.
According to the study of the status of faculty women in science at MIT, "While there was variation between departments, a common finding for most senior women faculty was that the women were 'invisible,' excluded from a voice in their departments and from positions of any real power" [27]. Interestingly, as junior faculty, these women had felt included and supported; "the 'marginalization' had occurred as the women progressed through their careers at MIT, making their jobs increasingly difficult and less satisfying" [27].

Third, some senior women may not wish to take on the role of mentoring junior women in particular, seeing this as a stereotypic role that adds to an already overloaded agenda. Others who do engage in mentoring young women faculty may do so in either ineffective or over-controlling ways.

For these reasons, cross-gender mentoring is the rule, and this reality sets the stage for relationships in which gender and status interact to produce all the confusions and dysfunctions present in crossgender relationships in a gender-privileged society. In particular, Kram has identified five major categories of cross-gender relationship complexities that can impede the mentoring relationship and may damage either the mentor or the protégé professionally and personally [28]. The most obvious complicating factor in cross-gender relationships is the development of intimacy and sexually-charged interactions. A second, less obvious obstacle is the adoption of stereotypical gender roles in the mentoring relationship such as parentchild or chivalrous knight-helpless maiden. Feist-Price provides a useful review and commentary on these issues in reference [29].

Finally, to the extent that senior male (or female) faculty either consciously or unconsciously adopt aspects of the "heroic male journey" as their mentoring model, they are likely to ill-serve female graduate students and young faculty. According to the generalized gender differences we have outlined, young women may be more comfortable responding to praise than to challenge, profit more from either non-affronting or non-aggressive challenges, perform better when supported rather than tested, seek peer collaboration rather than competition, and may wish to construct their careers (and lives) around different priorities than their male counterparts. These differences motivate the search for alternative mentoring strategies that are informed by, and cater to, societally-constructed differences between men and women.

\section{B. Alternative Mentoring Models}

Hall and Sandler provide examples of innovative mentoring programs useful for women, and especially for women in non-traditional fields (like SME) as well as "older" women, "minority" women, and "disabled" women [30]. More recently, Tierney and Bensimon have argued that "The notion of a single experienced faculty member being willing and able to play the all-inclusive role of mentor to a protégé is wishful thinking" [31]. In truth, a variety of individuals are required to help meet a mentee's diverse needs. Ragins and Cotton also make a strong case against reliance on the single mentor model, arguing that "It is important for organizations to avoid sending the implicit message that once a protégé has an assigned (formal) mentor, this mentor is sufficient and that they should not attempt to gain an informal mentor" [17]. Both the diversity of younger professionals and their diverse needs, and the performance pressures and interest level of older faculty, mitigate against this "lone helper" model.

1) Model 1: Multiple Mentoring: In an alternative model that can be conceptualized as either a spider web or Venn diagram of interconnected circles, multiple mentoring encourages the protégé to 
construct a mentoring community based on a diverse set of helpers instead of relying on a single mentor. Humphreys [32] discusses the possibilities of "distributed mentorship", which includes as mentors both senior and junior colleagues, people inside as well as outside the academy, and electronic media as well as personal connections. In a pamphlet created by the University of Michigan for graduate students, potential protégés are advised to build "a mentoring team" and are reminded that "by having a team of mentors, you will not be harmed in any way if you work with someone who truly has limited access to the powerful networks of your discipline" [26]. In a parallel pamphlet created for faculty, potential mentors are advised "to help students cultivate multiple mentoring relationships inside and outside the university" [33].

Galbraith \& Maslin-Ostrowski argue for the importance of long-term mentoring by a mentoring team [34]. They point out that it is important for mentoring team members "to establish a relationship with future mentees early in the students' academic careers. This would be accomplished in part through active listening and questioning that establishes a psychological climate of trust. This trust lays the foundation for a more engaging mentoring relationship. Without this type of connection, the likelihood of a meaningful mentor-mentee experience is limited" [34]. Several other researchers emphasize the importance of early mentoring whatever the educational or career stage of the female scientist: "Early inclusion in a strong network (of professional contacts) provides a 'jump start' to a scientific career" $[14,35]$.

Some of these ideas have been tested by Packard [23], who has devised an intervention program aimed at helping protégés assemble a diverse set of mentors into a "composite mentor." Suggesting that young scholars consider the attractive traits of different role models in their environment, she argues that the composite mentor is especially promising for women in SME because they "struggle with the lack of mentor images in the field... It would help women make use of the available images in their environment" [23] including men and people from different backgrounds. The disadvantage of this approach is that the burden of community-building is laid upon the protégé. Also, finding a diverse set of helpers who meet the various and changing needs of the protégé in a new institution and presumably new career stage is not a trivial task.

2) Model 2: Peer Mentoring: Peer mentoring represents another alternative mentoring strategy that simultaneously builds community and de-emphasizes seniority and hierarchy. It also has been offered as a strategy that "may embody a more feminist construct for promoting women in academia" [36]. Female friendship circles and study groups may help women SME students learn material and support one another while avoiding openly competitive or negative interactions with men. Limbert has described her personal experiences in a group for academic faculty and staff women that encourages support "across boundaries and disciplines,... [and] between disciplines and/or departments" [37]. In addition to the development of a broad and diverse professional community, Limbert promotes the flexibility and informality of peer mentoring relationships that enable women to "drop in and drop out." More generally, this flexibility in time and level of commitment directly addresses problems women often experience with the traditional mentoring model; that is, unpredictable family and child-care responsibilities and career interruptions. While peer mentoring strategies are worth further study, Chandler has predicted three main obstacles to their long-term success which all arise from the abolition of the traditional hierarchy: "The competitive position that peers often find themselves in, lack of experience, and the difficulty that may arise if their careers advance at different rates" [36]. Struggle over whose needs are met when is another possible complication in this multiple mentor/multiple mentee strategy. Etkowitz emphasizes that such peer-generated or "bottom up" strategies only will be successful if powerful senior faculty and departmental leaders support such efforts and provide them with necessary resources and affirmation [14].

3) Model 3: Collective Mentoring: Collective mentoring is an evolution of the multiple mentor/single mentee model whereby senior colleagues and the department take responsibility for constructing and maintaining a mentoring team. Thus, mentoring becomes neither an individual one-on-one activity, nor one solicited and designed solely by the protégé. Instead, an entire department or organization must establish and ensure the effective mentoring and performance of graduate students and young professionals. In this way, senior colleagues and the department itself send the message that their progress is a priority concern and may create a departmental climate that overcomes some of the obstacles not only to effective mentoring of women, but also to their effective performance, retention and advancement. As Seymour and Hewitt argue, an effective program must have a "public commitment of senior administrators and departmental chairs. Successful programs draw upon the knowledge of senior women students and female faculty who know how the culture of S.M.E. departments work. They also employ the help of sympathetic male faculty as a network of mentors from professional work settings" [24].

Tierney and Bensimon [31] point out that collective mentoring is a formal and collective organizational task, part of the organization's responsibility to orient and socialize its new members. As such, "mentoring need not take place only in a senior faculty member's office or an orientation session at the beginning of the school year. The mail room, the faculty lounge, and any number of other institutional locations have potential for socializing individuals to the culture of the department and organization" [31]. Ginorio argues that women and people of color, especially, need to find a meaningful community in science and engineering, one that "would not include... outdated ideas of what a successful culture of science is: competitive, all engrossing, demanding to the exclusion of any other interest, and open only to the handful of individuals who can pass all the tests of misunderstood manhood that are demanded today" [9]. Organizational change that creates more egalitarian and caring communities will benefit men as well as women.

\section{Organizational Change}

We have argued that mentoring is an important component of efforts to improve the presence, retention and advancement of women faculty and graduate students in engineering, and that women scholars in SME who seek mentoring relationships face a number of special challenges and obstacles. Some of these obstacles are generated by men and women's prior socialization, expectations and styles. Some are generated by peer gender dynamics and by the dynamics of inter-status mentoring across gender lines. Some are generated and reinforced by the culture, time and work expectations, tenure clock, and reward systems of the male-centered academy. Even when these organizational pressures are applied universalistically (e.g., without either apparent prejudice or bias) they have differential impact on male and female scientists. 
Successful mentoring of women in SME must recognize the different cultural styles or worldviews of men and women, the diverse needs and styles of women from different cultural and class backgrounds, the needs of women (and many men) for supportive and nurturing relationships in the midst of a highly stressful and competitive profession, the different experiences of men and women in the scientific enterprise, and the socially-constructed and institutionally-supported dynamics of gender privilege that affect cross-gender relationships. While attention has begun to be paid to the special interpersonal sensitivities and political tactics that might be important in mentoring women graduate students and faculty, our particular concern has been with alternative models of the mentoring relationship itself, especially ones that originate from and cater to women's cultural styles.

However, new approaches to mentoring, by themselves, will not suffice to overcome the career barriers and disadvantages faced by women in SME. Mentoring is only one element to be considered in efforts to alter the culture and structure of the academy. In constructing a broader approach for improving women's ability and success in navigating the scholarly track in engineering, we draw from others' analyses of work organizations that dominate employees' lives. As Maier summarizes Argyris, in Model I (single loop learning) approaches, "we accept existing constraints as given, and we seek ways to enhance our performance... within and consistent with that worldview" [8]. Translated as "work within the system," this is conventional wisdom for junior people in any discipline. However, Model II (double loop learning) approaches "allow us to call the existing worldview itself into question" [8]. That is, at times one must challenge the traditional and orthodox image of a successful career pattern. In "greedy" institutions (those which require enormous time and energy commitments by male and female employees), it may be that institutional change through challenge is the only way for women (and men) to live full and fully integrated personal and professional lives. Successful mentors must assist in these challenges and changes: "Faculty who make the best mentors... buttress their female students against the 'slings and arrows' of outrageous treatment. Sometimes they are willing to advocate changes, going against prevailing conservative academic ethos with respect to academic practices" [14].

Thus, the effort to more effectively mentor women in the sciences and engineering will require change not only in how we think about mentoring, but also in how we think about broader faculty roles and institutional structures. Specifically, senior faculty, most of whom are male, may well need special training in implementing more effective mentoring of women and cross-gender mentoring relationships $[31,38]$. (See also references [26] and [33]). Such training programs have already been developed in industrial and corporate settings. In order for the potential benefits of mentorship to be realized, the organization's reward system, culture, norms and definitions of tasks and functions must value and encourage relationship-building activities as central to organizational goals and objectives. For example, the mentoring activities of senior colleagues could be included in yearly evaluations and used in part to determine salary increases as a subset of the service category. The relevance of new departmental norms is crucial to the success of mentoring of any sort. As Seymour and Hewitt note, "without honest attempts by S.M.E. departments to confront and address the norms and practices which make it difficult for women to persist - including increasing the willingness of faculty to be the main source of mentoring for all students and the appointment of more female faculty and teaching assistants - the addition of mentoring services is unlikely to make other than marginal improvements in the attrition rates for women" [24].

Morgan argues further that "transforming our institutions to better serve the needs of women must include serious new kinds of hiring and retention programs, financial incentives for change, and circulating data on successful programs" [38]. Above all, it must include guaranteeing the presence of and respect for senior and powerful women, women who can effectively mentor younger women in their fields. Indeed, the entire discussion of mentoring young women simultaneously stems from this lack and seeks to redress it. Any of these efforts will require a "planned, deliberate change in the ethos of the academy" [39] as well as in its internal structures and relations with external constituencies.

None of this is likely to be easy. Institutional change and transformation, however necessary, is not to be undertaken lightly. However, there is precedent both in industry and in the academy. Research on planned change processes related to gender relations and gender equity in organizations has a relatively short but rich history (see references [40-45] for example). As a resource for our colleagues desirous and empowered to create lasting and successful institutional transformation, we recreate here Maier's table of alternatives to organizational systems and practices that stem from traditionally-male cultural styles. (See Table 2). When applied to mentoring strategies for women in science, mathematics, and engineering, these concepts

\begin{tabular}{|c|c|c|c|c|}
\hline & $\begin{array}{l}\text { Characteristics of } \\
\text { "Feminist } \\
\text { Organizational } \\
\text { Structures" [46] }\end{array}$ & $\begin{array}{l}\text { Characteristics of a } \\
\text { "Feminine Model of } \\
\text { Organization" [4] }\end{array}$ & $\begin{array}{l}\text { Practices of "Feminist } \\
\text { Management" [48] }\end{array}$ & $\begin{array}{l}\text { Characteristics of } \\
\text { Women-Led } \\
\text { Organizations [7] }\end{array}$ \\
\hline $\begin{array}{l}\text { Decision-making } \\
\text { strategy }\end{array}$ & $\begin{array}{l}\text { Work from democratic } \\
\text { authority }\end{array}$ & $\begin{array}{l}\text { Value members as } \\
\text { individuals }\end{array}$ & $\begin{array}{l}\text { Promote subordinate } \\
\text { empowerment }\end{array}$ & $\begin{array}{l}\text { Build consensus and } \\
\text { circular structures }\end{array}$ \\
\hline Leadership strategy & Coordinate and facilitate & Share power & $\begin{array}{l}\text { Be responsive to diverse } \\
\text { circumstances; } \\
\text { contextualize issues }\end{array}$ & $\begin{array}{l}\text { Operate from the center, } \\
\text { not the top }\end{array}$ \\
\hline $\begin{array}{l}\text { Motivation and long } \\
\text { term goals }\end{array}$ & $\begin{array}{l}\text { Share knowledge and } \\
\text { skills } \\
\text { Connect mental and } \\
\text { manual labor }\end{array}$ & $\begin{array}{l}\text { Define careers in terms } \\
\text { of service to others } \\
\text { Create a caring } \\
\text { community }\end{array}$ & $\begin{array}{l}\text { Seek transformational } \\
\text { outcomes for } \\
\text { (a) individual women, } \\
\text { (b) women collectively, } \\
\text { (c) men, and } \\
\text { (d) the organization }\end{array}$ & $\begin{array}{l}\text { Serve as a vehicle for } \\
\text { continuous } \\
\text { improvement }\end{array}$ \\
\hline
\end{tabular}

Table 2. Conceptual alternatives to traditional male culturalstyles in selected organizational tasks and goals. (Adapted from reference [8]). 
should generate systems that fit more readily with women's cultural styles and, thus, meet their needs and expectations.

The implications of these concepts are that mentoring systems that stem from and lead to more inclusive, participatory and democratic organizational structures, that value junior (and senior) members as individuals with emotional and practical as well as intellectual needs and interests, and that share resources broadly in the effort to help members improve their personal as well as collective outcomes will be more effective for many women in SME and many younger men as well. Etkowitz presents a similar argument in distinguishing between departments with an "instrumental" or a "relational" culture. Whereas in instrumentally-focused departments "interpersonal interactions are minimal and open communication avoided," in relational departments there is a "collegial and cooperative atmosphere that provide the safety to take the risks necessary for innovative work and the collaboration necessary for networking" [14]. They conclude that the relational departments are most successful in attracting, retaining and advancing the professional achievements of women faculty.

Although these transformational objectives are important, we recognize that they are beyond the resources of many departments and colleges. In their absence, major revisions of the mentoring process that we have discussed here can and should be implemented. Perhaps the most important alternative perspective is a negation: the successful graduate student or faculty track in SME need not follow the pattern of a heroic journey. Junior scholars and faculty members can be encouraged to meet their potential rather than having it continually questioned, and assumed and aided to be successful. These ideas represent a social contract for the creation of a transforming and caring community.

\section{CONCLUSIONS}

Given the multiple tasks young scholars must learn to perform (e.g., learning and developing unique SME competencies, teaching and conducting research, publishing, navigating new jobs and institutions, and planning careers) multiple and collective mentorships will be more successful systems for advancing the careers of young women scholars in engineering. These mentoring activities require departmental and institutional commitment and must provide access to women faculty and especially to supportive senior women faculty, informational and technical guidance, nurturing interpersonal relationships, and a "warmer departmental climate" for women. Mentoring of women must also acknowledge and respond to the special ways in which women negotiate previously maledominated environments, maintain their unique personal and cultural identities, and balance career and family expectations and relationships. Above all, mentoring must be seen as more than an individual activity and other than a heroic challenge or test.

The larger goal of organizational change is not to accelerate the assimilation of women into the existing system, but to provide support, make the most positive value of gender (and racial) diversity, and engage people with different skills, styles and values in the effort to improve the organizational environment. Successful mentoring of women engineering scholars rests on, and can help create a more egalitarian and cooperative academic community which is also more caring and promotes all members' personal and professional growth and success.

\section{ACKNOWLEDGMENTS}

This material is based upon work supported by the National Science Foundation CAREER Grant Number 9985012 (NCC).

\section{REFERENCES}

[1] National Science Foundation/SRS, 1995 SESTAT Integrated Data System, Unpublished tabulation created by the authors.

[2] Daniels, J., "Population and Pipeline," Bridging the Gender Gap in Engineering and Science, Carnegie Mellon University, Pittsburgh, PA, 1995.

[3] AAMC Reporter, vol. 9, no. 3, 1999.

[4] Nonnemaker, L., "Women Physicians in Academic Medicine: New Insights from Cohort Studies," New England Journal of Medicine, vol. 342, 2000, pp. 399-405.

[5] Meyerson, D., and J. Fletcher, "A Modest Manifesto for Shattering the Glass Ceiling," Harvard Business Review, 2000, pp. 127-136.

[6] Gilligan, C., In a Different Voice: Psychological Theory and Women's Development, Harvard University Press, Cambridge, MA, 1982.

[7] Helgesen, S., Female Advantage: Women's Ways of Leadership, Doubleday Currency, New York, NY, 1995.

[8] Maier, M., "On the Gendered Substructure of Organization," Handbook of Gender \& Work, G.N. Powell, Ed., Sage Publications, Thousand Oaks, CA, 1999.

[9] Ginorio, A., "A Culture of Meaningful Community," Bridging the Gender Gap in Engineering and Science, Carnegie Mellon University, Pittsburgh, PA, 1995.

[10] Seymour, E., "The Loss of Women from Science, Mathematics and Engineering Undergraduate Majors," Science Education, vol. 79, no. 4, 1995, pp. 437-473.

[11] National Research Council Board on Engineering Education, Report on Designing an Adaptive System, National Academy Press, Washington, D.C., 1995.

[12] Strenta, C., et al., Choosing and Leaving Science in Highly Selective Institutions: General Factors and the Question of Gender, Report to the Alfred P. Sloan Foundation, 1993.

[13] Astin, A., and H. Astin, Undergraduate Science Education: The Impact of Different College Environments on the Educational Pipeline, UCLA Press, Los Angeles, CA, 1993.

[14] Etkowitz, H., C. Kemelgor, and B. Uzzi, Athena Unbound: The Advancement of Women in Science and Technology, Cambridge University Press, NY, 2000.

[15] Hall, R., and B. Sandler, Out of the Classroom: A Chilly Campus Climate for Women?, Association of American Colleges, Washington, DC, 1984.

[16] Cole, J., Fair Science: Women in the Scientific Community, The Free Press, New York, 1979.

[17] Ragins, B., and J. Cotton, "Mentor Functions and Outcomes: A Comparison of Men and Women in Formal and Informal Mentoring Relationships," Journal of Applied Psychology, vol. 84, no. 4, 1999, pp. 529-550.

[18] Ambrose, S., et al., Journeys of Women in Science \& Engineering, Temple University Press, Philadelphia, PA, 1997.

[19] Clark, S., and M. Corcoran, "Perspectives on the Professional Socialization of Women," Journal of Higher Education, vol. 57, no. 1, 1986, pp. 20-43.

[20] Broome, T., "The Heroic Mentorship," Science Communication, vol. 17, no. 4, 1996, pp. 398-429. 
[21] Broome, T., “The Heroic Engineer," Journal of Engineering Education, 1997, vol. 86, no. 1, 1997, pp. 51-55.

[22] Baum, E., "Setting the Stage," Bridging the Gender Gap in Engineering and Science, Carnegie Mellon University, Pittsburgh, PA, 1995.

[23] Packard, B., “A 'Composite Mentor' Intervention for Women in Science," American Educational Research Association Annual Meeting, Montreal, QC, 1999.

[24] Seymour, E., and N. Hewitt, Talking About Leaving: Why Undergraduates Leave the Sciences, vol. 79, Westview Press, Boulder, CO, 1997, p. 302.

[25] Wankat, P., and F. Oreovicz, Teaching Engineering, McGraw Hill, New York, NY, 1993.

[26] Rackham School of Graduate Studies, How to Get the Mentoring You Want, University of Michigan, Ann Arbor, MI, 2000.

[27] Committee on Women Faculty in the School of Science, A Study on the Status of Women in Science at MIT, Massachusetts Institute of Technology, Cambridge, MA, 1999.

[28] Kram, K., Mentoring At Work, Scott, Foresman \& Co., 1985.

[29] Feist-Price, S., "Cross-Gender Mentoring Relationships: Critical Issues," Journal of Rehabilitation, April-June, 1994, pp. 13-17.

[30] Hall, R., and B. Sandler, Academic Mentoring for Women Students and Faculty: A New Look at an Old Way to Get Ahead, Association of American Colleges \& Universities, Washington, DC, 1983.

[31] Tierney, W., and E. Bensimon, Promotion and Tenure: Community and Socialization in Academe, State University of New York Press, Albany, NY, 1996.

[32] Humphreys, S., "The Role of Women Graduate Students," Bridging the Gender Gap in Engineering and Science, Carnegie Mellon University, Pittsburgh, PA, 1995.

[33] Rackham School of Graduate Studies, How to Mentor Graduate Students, University of Michigan, Ann Arbor, MI, 2000.

[34] Galbraith, M.W., and P. Maslin-Ostrowski, "Chapter Six: The Mentor Facilitating Out-of-Class Cognitive and Affective Growth," Teaching Alone, Teaching Together: Transforming the Structure of Teams for Teaching, James L. Bess and Associates, Eds., Jossey-Bass, San Francisco, CA, 2000, pp. 145-148.

[35] Ginorio, A., Warming the Climate for Women in Academic Science, Association of American Colleges and Universities, Washington, DC, 1995.

[36] Chandler, C., "Mentoring and Women in Academia: Reevaluating the Traditional Model," NWSA Journal, vol. 8, 1996.

[37] Limbert, C., "Chrysalis, A Peer Mentoring Program for Faculty and Staff Women," NWSA Journal, vol. 7,1995.

[38] Morgan, G., "Highlights from Bridging the Gender Gap," Bridging the Gender Gap in Engineering and Science, Carnegie Mellon University, Pittsburgh, PA, 1995.

[39] Nair, I., and B. Lazarus, "Towards a Theory of Institutional Transformation," Bridging the Gender Gap in Engineering and Science, Carnegie Mellon University, Pittsburgh, PA, 1995.

[40] Ely, R., Feminist Critiques of Research on Gender in Organizations, Center for Gender in Organizations, Simmons Graduate School of Management, 1999.

[41] Fagenson, E. (Ed.), Women in Management: Trends, Issues and Challenges in Managerial Diversity, SAGE Press, Newbury Park, CA, 1993.

[42] Kanter, R., Men and Women of the Corporation, Basic Books, New York, NY, 1977.

[43] Mills, A., and Trancred, P. (Ed.), Gendering Organizational Analysis, SAGE Press, Newbury Park, CA, 1992.
[44] Powell, G. (Ed.), Handbook of Gender and Work, SAGE Press, Newbury Park, CA, 1999.

[45] Sargent, A., The Androgynous Manager, American Management Association Communications, New York, NY, 1981.

[46] Ferguson, K., Lessons from Challenger (symposium), GTE Lectureship in Technology and Ethics, Binghamton, NY, 1991.

[47] Rothschild, J., Principles of Feminist Trade Union Organizations, Presented at the Workshop of Feminist Organizations, Washington, DC, 1992.

[48] Martin, P., "Feminist Practice in Organizations: Implications for Management," Women in Management: Trends, Issues and Challenges in Managerial Diversity, E. Fagenson, Editor, SAGE Press: Newbury Park, CA, 1993.

\section{AUTHOR BiograpHIES}

Naomi C. Chesler received her B.S. in Engineering from Swarthmore College, M.S. in Mechanical Engineering from MIT and Ph.D. in Medical Engineering from the Harvard-MIT Division of Health Sciences and Technology. She has been an Assistant Professor of Mechanical Engineering at the University of Vermont and recently joined the Biomedical Engineering Department of the University of Wisconsin. In addition to her research into the clinically relevant effects of mechanical forces on vascular biology, Dr. Chesler teaches undergraduate and graduate level fluid dynamics and biofluid dynamics. She acknowledges and appreciates the mentoring and advising she has received over the years from her thesis advisors, senior faculty members, colleagues and students.

Address: Biomedical Engineering, University of WisconsinMadison, 1410 Engineering Drive, Madison, WI 53706-1608; telephone: 608-263-4660; Fax: 608-265-9239; e-mail: Chesler@ engr.wisc.edu.

Mark A. Chesler is Professor of Sociology at the University of Michigan, former Director of Graduate Studies, and of Undergraduate Studies. He has published widely in the area of race and gender discrimination in higher education and the impact of chronic childhood illness on the family. The Drs. Chesler are a daughterfather team.

Address: 4028 LSA Building, University of Michigan, Ann Arbor, MI, 48109; telephone: 734-647-3654; e-mail: mchesler@ umich.edu. 